\title{
As misericórdias e as transferências de bens: o caso dos Monteiros, entre o Porto e a Ásia
} (1580-1640)

\author{
Isabel dos Guimarães Sá[1]
}

\begin{abstract}
Resumo
Os testamentos de dois mercadores da mesma família, envolvidos na viagem do Japão, Antônio e Domingos Monteiro, revelam um modo de vida marcado pela mobilidade entre vários territórios do Sudeste Asiático, transacionando grande variedade de produtos. Por meio de sua rede de relações, é possível discernir a presença de parentes seus, sobretudo sobrinhos, e de outros negociantes portuenses, sugerindo que o modelo português de emigração para o Brasil já estava em ação no Oriente. Embora a transmissão de bens competisse aos provedores dos defuntos e ausentes, as misericórdias transferiam capitais de defuntos para a metrópole, em detrimento dos agentes diretos do rei, embora fosse impossível evitar a ingerência destes últimos. Apesar da vontade em fazer chegar o dinheiro à metrópole rapidamente para convertê-lo em padrões de juro, conveniências do trato, a burocracia régia e litígios sucessórios tornavam moroso o processo de transferência.
\end{abstract}

Palavras-chave: transmissão de propriedade; Misericórdias Portuguesas; Misericórdia do Porto; Ásia portuguesa

\section{The confraternities of Misericórdia and property transfers: the case of the Monteiro family, between Porto and Asia (1580-1640)}

\begin{abstract}
This study focuses on two persons of the same family, Antônio e Domingos Monteiro, both involved in the Japan trade, whose way of life was marked by mobility within the coasts of South East Asia, trading in a wide variety of goods. Their network of contacts reveals the presence of members of their kin, especially nephews, as well as merchants from Porto, suggesting that the Portuguese model of emigration to Brazil during the nineteenth century was already at work in Asia. The purveyors of the dead and absentees were in charge of transmitting assets to inheritors in Portugal, but the misericórdias also performed this role, even if in practice the interference of the representatives of the king was impossible to avoid. In spite of the intention of directing the money to mainland Portugal as soon as possible, long voyages, conveniences of maritime trade, royal bureaucracy and judicial litigations transformed transfer into a morose process.
\end{abstract}

Keywords: transmission of property; Portuguese confraternities of Misericórdia; Misericórdia do Porto; Portuguese Asia.

\section{Les confréries de Misericórdia et les transferts de propriété : le cas de la famille Monteiro, entre Porto et l'Asie (1580-1640)}

\section{Résumé}

Cet article étudie deux hommes de la même famille, impliqués dans le voyage du Japon, Antônio et Domingos Monteiro, leur mode de vie étant marqué par une constante mobilité au Sud-est Asiatique, grâce au commerce d'une grande variété de produits. Leur réseau de contacts démontre la présence d'autres membres de leur famille en Asie, surtout des neveux, suggérant que le modèle de l'émigration portugaise au Brésil était déjà à l'œuvre dans l’Est. Les « provedores » dés défunts et absents devaient assurer le transfert de richesse aux héritiers, mais les confréries de misericórdias jouaient aussi ce rôle au détriment des agents du roi, quoique il était en pratique impossible d'éviter l'ingérence de ces derniers. Malgré la volonté de faire arriver rapidement l'argent à la métropole, la durée des voyages, les contingences du commerce, la bureaucratie royale et les conflits entre les héritiers transformaient ce transfert dans un procès morose. Mots-clefs: transmission de propriété ; confréries portugaises de Misericórdia ; misericórdia de Porto ; Asie portugaise.

Las cofradías de Misericordia y las transferencias de bienes: el caso de los Monteiro. entre Porto y Asia (1580-1640)

\section{Resumen}

Este estudio se basa en dos personas de la misma familia, ambos implicados en el viaje a Japón, António y Domingos Monteiro. Su modo de vida muestra su grande movilidad en la costa Sudeste de Asia, a través del comercio de una amplia variedad de productos. Otros miembros de su familia, especialmente sobrinos, estaban presentes, lo que sugiere que el modelo de emigración portuguesa a Brasil ya estaba en acción en el Oriente siglos antes.

Era la función de los proveedores de los muertos y ausentes garantizar la transferencia de bienes, aunque las misericordias también desempeñaran estas funciones, en detrimento de los agentes directos del rey, aunque en la práctica fue imposible evitar la interferencia de estos últimos. A pesar de la voluntad de transferir el dinero a la metrópoli con rapidez, la duración de los viajes, las conveniencias de lo trato, la burocracia regia y los conflictos entre los herederos hacían largo este proceso.

Palabras clave: transmisión de herencias; cofradías portuguesas de Misericórdia; Misericórdia do Porto; Asia portuguesa 
As misericórdias e as transferências de bens: o caso dos Monteiros, entre o Porto e a Ásia (1580-1640)

No último vintênio do século XVI, o viajante que aportasse a Macau poderia encontrar numerosos homens com o sobrenome Monteiro. Muitos deles pertenciam à família portuense do mesmo sobrenome, em uma mistura entre legítimos e bastardos que não seria invulgar na época. Os nobiliários apontam-nos como família fidalga da cidade do Porto, com pedra de armas concedida pelo rei d. João III, para substituir certificados mais antigos, uma vez que, a acreditar no que dizem, a linhagem já existia muito antes (Morais, 1998, p. 96-102; Gaio, 1939, p. 187-213). ${ }^{2}$ Como muitas famílias portuenses, os Monteiros tinham um pé em zonas rurais relativamente distantes, nesse caso Mesão Frio, na região do Douro, onde vivia parte da família. Este artigo debruça-se sobre os testamentos de dois deles; o de Antônio Monteiro é de 1580, e o Domingos Monteiro, de 1591, declarando o primeiro ser tio do segundo. ${ }^{3}$ Não é no entanto de supor que a diferença de idades fosse necessariamente grande, como é o caso de tios e sobrinhos em famílias de prole numerosa ou espaçada.

\section{Antônio Monteiro}

Corria o mês de abril de 1580 quando Antônio fez seu testamento. ${ }^{4} \mathrm{O}$ modo como o abria era pouco comum: declarava à cabeça que seu pai, Gil Monteiro, era casado ao tempo de seu nascimento com uma mulher chamada Inês do Couto. A mãe de Antônio era uma "mulher solteira que [o pai] tinha em sua casa”, Madalena Pires, que, entretanto, se casara. ${ }^{5}$ Ou seja, Antônio era um bastardo, e não um filho natural, uma vez que esta última designação era exclusiva para aqueles cujos pais podiam se casar entre si (Sá, 1994, p. 73). Gil Monteiro muito provavelmente teve filhos das duas mulheres ao mesmo tempo, e também na mesma casa. $\mathrm{O}$ fato de Madalena ter depois se casado indicia que alguma proteção deve ter recebido; uma mulher raramente se casava sem dote, ainda mais sendo mãe de filhos. É plausível que alguém na família Monteiro o tenha pago, muito provavelmente Gil, uma vez que os nobiliários nos dizem que foram quatro os bastardos havidos com essa mulher, embora, a acreditar nas múltiplas inexatidões que detectamos, possam estar errados. ${ }^{6}$ Se essa situação familiar causou conflitos e sofrimento, não sabemos, mas o fato é que

\footnotetext{
2 Adverte-se, no entanto, que detectamos erros, conforme adiante reportaremos. Sobre essa família, ver também Brito (1997, p. 377). Domingos Monteiro foi também estudado por Freitas (1991, p. 389-393).

${ }^{3}$ A menos que se declare o contrário, as principais fontes usadas neste artigo serão Arquivo Histórico da Santa Casa da Misericórdia do Porto (AHSCMP), série H, banco 4, livro 29, fls. 1-24O (testamentaria de Antônio Monteiro), e série H, banco 6, livro 17, fl. 280v e segs. (Domingos Monteiro). Apenas as citações ipsis verbis serão objeto de referenciação exata.

${ }^{4}$ Sobre as questões relacionadas com aspetos formais da feitura de testamentos, ver Araújo (1997, em especial p. 271-273)

${ }^{5}$ AHSCMP, série H, banco 4, livro 29, fl. 19.

${ }^{6}$ A mais grave é que a faz Domingos Monteiro Filho de um irmão também bastardo de Antônio; é impossível, uma vez que o primeiro declara em seu testamento ser filho de Branca da Rocha e Antônio Monteiro (ver nota 2).
} 
configurações semelhantes não eram invulgares na época, antes de as reformas religiosas terem segregado os filhos ilegítimos. Embora não fosse vulgar um homem viver na mesma casa com duas mães de filhos seus, era comum não só dar seu sobrenome aos ilegítimos, quando os reconhecia (o que nem sempre era o caso), como também retirá-los às mães para criá-los em família juntamente com os filhos de seu casamento. O estatuto de bastardo de Antônio não o impediu de se declarar criado do duque de Bragança e seus descendentes, com assentamento em seus livros, e de relembrar os serviços prestados ao rei com suas armas, tendo vindo assentado para a Índia, tudo certificado por papéis que tinha em sua posse. Ou seja, como tantos outros, Antônio chegara à Ásia em um contingente de soldados e por lá se dedicara ao comércio.

Antônio Monteiro, todavia, recordava sua bastardia com uma finalidade: a de declarar que as leis do direito divino e humano impediam sua mãe de ser sua herdeira, conforme informações que tinha tanto das Ordenações do Reino quanto de teólogos. Ele revelava-se bem informado não só sobre o que fora feito de sua mãe (julgava-a viva e sabia-a casada) quanto no que respeita às leis de Deus e dos homens. No entanto, acabou por contemplá-la com 300 cruzados (120 mil réis), uma soma muito substancial para a época. Antônio nomeava o primeiro de uma pequena multidão de outros Monteiros, além do pai, entre tios, sobrinhos e escravos de sua propriedade; como se sabe, estes últimos podiam receber o sobrenome do dono, conforme o costume da época. Entre os sobrinhos, Gil Monteiro Pinto, morador do Porto, que, juntamente com seus testamenteiros, devia fazer chegar o dinheiro à sua mãe ou aos herdeiros do novo casamento desta, filhos e marido. Pelo que se passou depois, sabemos que Gil era filho de seu único meio-irmão legítimo e tinha se casado com Luísa de Paiva de Azevedo.

\section{O enterro}

Antônio devia saber que morreria em breve, porque organizou seu funeral para Macau, onde se encontrava. O corpo iria para sua igreja grande, para o pé do altar de São Francisco; continuava uma tradição familiar, uma vez que a nobreza de sua cidade natal, o Porto, preferia o convento franciscano para última morada. Os irmãos da misericórdia o acompanhariam. Nada que fosse gratuito, embora esse dinheiro se enquadre na categoria do dom, uma vez que Antônio o dava voluntariamente, ficando os montantes a seu arbítrio. Os franciscanos recebiam 20 cruzados, e a misericórdia, 200, em uma proporção que fala bem acerca da importância institucional relativa de ambos, ainda que o dinheiro recebido pela segunda fosse "para pobres". Nomeava outras cinco confrarias da cidade, todas agraciadas com dinheiro, e ainda uma casa de franciscanos capuchinhos. Para encomendar sua alma, devia fazer-se o tradicional ofício de nove lições, uma celebração litúrgica noturna muito demorada (de nove leituras, como o nome indica), preenchendo a noite do velório. Não seria o único, uma vez que se celebraria um segundo daí a 15 dias, e outro ao 
fim de um mês do falecimento. Dir-se-iam ainda 30 missas, cinco em honra das cinco chagas de Cristo, três à do Espírito Santo e nove a Nossa Senhora da Conceição, sendo as restantes de réquiem por sua alma e de seus defuntos. Mais tarde, já em um codicilo, beneficiaria também a poderosa Companhia de Jesus. Não é de estranhar essa súbita aparição da Companhia; os codicilos faziam-se para corrigir ou acrescentar legados, e entre testamento e codicilo muitas influências se moveriam.

\section{Violante e Isabelinha}

Apesar de legar à sua mãe uma soma substancial, era em torno de uma menina que se organizavam as preocupações principais de Antônio Monteiro. Nascera em casa, de uma moça, provavelmente uma escrava asiática batizada, como o nome de Maria Monteiro deixa supor. Chamava-se Violante, e deixava-lhe uma fortuna para seu futuro casamento: 4 mil cruzados, ou seja 1,6 conto, uma soma muito alta para finais do século XVI. A menina ficaria a cuidado dos testamenteiros, que usariam esse dinheiro para comprar seda em Macau e levariam a Goa o produto da venda. Domingos Monteiro (nosso segundo testador), que Antônio designa como tio de Violante, receberia esse dinheiro na Índia, e, juntamente com outro Monteiro, seu irmão Rodrigo, seria tutor e curador da criança. Antônio recomendava que o dinheiro não fosse dado a ganhos e dele só se retiraria o essencial para alimentos. Clarificava que não se tratava de uma herança, e não queria a ingerência de representantes do rei. Ou seja, Violante não era herdeira, porque o capital que lhe doava era a título de dote, o que permitia a Antônio nunca declarar abertamente que era sua filha. Preferia deixar o dinheiro nas mãos de quem confiava a permitir que o débil Estado português tratasse do assunto.

Antônio Monteiro providenciava ainda a favor de outra menina, a quem chama sempre Isabelinha, dessa vez uma órfã, filha de seu sobrinho Brás Pinto, que ficaria também a cargo dos irmãos Domingos e Rodrigo, que a casariam, embora com um dote quatro vezes menor, de mil cruzados. Os dados relativamente a esta são confusos, uma vez que Antônio tinha uma escrava de mesmo nome. Podem ser a mesma pessoa, o que não é inverosímil, uma vez que Brás podia ter tido uma filha de uma escrava. Pode tratar-se de um entre tantos casos de ambiguidade dos portugueses para com as famílias que criavam nos territórios longínquos de Portugal. Reconheciam filhos de mulheres com quem não se casavam, sendo muitas delas escravas com quem mantinham relações duradouras ou temporárias; as mães desapareciam ou permaneciam na sombra, mas os filhos ficavam a cargo dos pais.

O testamento deixa entrever que ambas as meninas estavam com Antônio em Macau, muito embora devessem voltar para a Índia, onde deixara "seu fato" ao cuidado de um escravo também chamado Monteiro (Brás), em quem confiava e que de resto lhe servia de agente comercial. Antônio refere no testamento 26 escravos seus, todos designados pelo nome, 18 do sexo masculino e 
oito do feminino, designados por "moços" ou meninos, de uma impressionante diversidade étnica: há chinas, sundas, japões e japoas, sioas e malaios. Dois deles estavam na Índia, supondo-se que os restantes estivessem com Antônio em Macau. Deve-se notar que Antônio afirmou ter comprado apenas quatro, a um preço de 20 a 30 cruzados cada, uma soma equivalente a 8.000-12.000 reais, certamente muito baixa. Outros eram declarados como tendo nascido em casa. Não é de excluir, no entanto, que alguns desses escravos fossem obtidos por rapto, que Patterson considera uma das formas mais correntes de escravização, até porque sabemos que os portugueses raptavam chineses nas aldeias (Patterson, 1982; Boxer, 1990, p. 229).

\section{Apesar de legar à sua mãe uma soma substancial, era em torno de uma menina que se organizavam as preocupações principais de Antônio Monteiro}

Antônio confessava que tinha uma casa, embora não diga onde, na qual vivia Violante com sua mãe; mas infere-se que fosse em Macau, onde estava à data de seu testamento, porque declara que devia ser vendida depois de sua partida, porque as meninas iriam para Cochim na nau da carreira, com o sobrinho Domingos e seu irmão Rodrigo Monteiro, seus tutores e curadores. Antônio deixava-lhes oito escravos para as servirem: Violante ficaria com seis moças e um rapaz, e Isabelinha, apenas com uma moça, em uma proporção que dá bem ideia da importância relativa das duas.

As meninas, Violante sempre mais do que Isabelinha, eram possuidoras de um conjunto de joias, que deviam conservar em sua posse depois da morte de Antônio. Estas eram consideradas adereços indispensáveis ao estatuto social das mulheres, uma vez que tornavam visível a qualidade e o preço de suas pessoas. O conjunto incluía cadeias e colares de ouro, manilhas (pulseiras), anéis e orelheiras (adornos de orelha à maneira oriental). Também uma pera de âmbar, e dezenas de botões de ouro, bem como um relicário de ouro com um agnus dei. E ainda alguma prata: dois copos, um saleiro, meia dúzia de facas, quatro colheres e quatro garfos. Também eles poderiam relembrar a Violante sua origem, uma vez que facas e garfos não eram instrumentos com que se comesse na Ásia. Dar-lhe esses objetos significava muito mais do que deixar-lhe bens materiais. Era uma operação de transferência cultural: a mãe de Violante seria talvez asiática, mas sua filha era chamada a partilhar a cultura portuguesa do pai por meio dos objetos cuja posse lhe transmitia. O relicário com o agnus dei filiava Violante na religião católica, ao passo que os instrumentos de mesa a remetiam para a cultura europeia. Violante seria sempre uma mistura entre um pai português e uma mãe asiática, embora o primeiro, ao reconhecer implicitamente a paternidade dela, estivesse a trazê-la para sua cultura. 
Deviam os curadores de Violante, Domingos e Rodrigo Monteiro, tratar de casá-la sem demora; o ideal fora que Domingos regressasse a Portugal, onde agenciaria seu casamento com "um homem nobre e honrado". Antônio depositava a máxima confiança em Domingos: "bem sei quanto seu tio lhe quer"? Caso Violante se casasse na Índia, se seu futuro marido quisesse ir viver em Portugal, a menina receberia 2 mil pardaus ${ }^{8}$ suplementares para acrescentar a seu dote. E vinham novamente as cláusulas de salvaguarda: se nem Domingos nem Rodrigo pudessem providenciar o casamento de Violante, a fazê-lo como testamenteira seria a misericórdia de Goa.

\section{O trato}

Antônio Monteiro, não o esqueçamos, era mercador. Andava na rota entre Índia e Japão, que passava obrigatoriamente por Macau. A cidade tinha-se tornado a "garganta", local de passagem e paragem incontornável para missionários e negociantes que desejavam penetrar na China ou ir ao Japão (Brockey, 2003, p. 44-55). Constituía também residência fixa de portugueses, sempre em número reduzido em relação à população chinesa que ia se fixando na cidade. ${ }^{9}$ Pela segunda metade do século XVIII, os habitantes portugueses representariam uma pequena fração dos residentes na pequena península, sempre dependentes da boa vontade política dos chineses para sobreviver, e também de todos os gêneros alimentares que estes lhes vendiam, uma vez que a exiguidade do espaço não permitia atividades de subsistência como a agricultura ou a criação de gado.

É difícil ler testamentos de negociantes, porque o dinheiro anda sempre na mão de vários parceiros, algumas vezes como investimento, outras no contexto de contas por saldar, em outras ainda como dívidas por cobrar. A informação neles contida por vezes é decalcada de livros de razão desaparecidos (Antônio Monteiro refere o seu), a partir dos quais se poderiam talvez historiar atividades comerciais. As que os testamentos documentam são as pendentes, ainda por resolver. Na condição de negociante, Antônio, como outros, andava no tráfico da seda chinesa, trocada pela prata do Japão. A prata era a moeda corrente na China, embora esta a produzisse em quantidades exíguas; não era monetarizada, sendo pesada cada vez que se fazia uma transação (Brook, 2009, p. 154), com base no tael, de peso variável de região para região. ${ }^{10}$

\footnotetext{
${ }^{7}$ Ambas as citações em AHSCMP, série H, banco 4, livro 29, fl. 32v (itálico nosso). Notamos aqui a ambiguidade das terminologias do parentesco usadas pelos próprios personagens históricos: Domingos era sobrinho de Antônio, mas tio da filha deste.

${ }^{8}$ Segundo Boxer, os pardaus podiam ser de ouro ou prata, tendo o primeiro o valor de 360 réis e o segundo, de 300 (Boxer, 1963, p. 336). O documento não especifica nenhum dos dois. Se fizermos a conta pelo valor mais baixo, teremos a muito significativa quantia de 60 mil réis, equivalente a três dotes de casamento de órfãs pobres.

9 Elsa Penalva (2005) acompanha a par e passo a presença de mercadores portugueses nas fontes documentais respeitantes à cidade de Macau, embora para um período posterior ao aqui tratado.

${ }^{10}$ Boxer refere que o tael era frequentemente equiparado ao cruzado, ao real de oito e ao ducado para propósitos de cálculo aproximado. Todas as equivalências relativas a pesos e moedas deste artigo foram feitas com base em Boxer (1963, p. 335-342).
} 
A "fazenda" que tinha andava embarcada, tendo sido enviada à Índia, a Timor, a Sião e ao Japão. Para a Índia, ia alguma seda que comprara na China, de Timor trazia sândalo, no Sião refere-se chumbo. O testamento menciona também Malaca e Cochim, onde um parceiro seu levaria taéis de ouro para pagar direitos das mercadorias. ${ }^{11} \mathrm{Na}$ nau do sobrinho Domingos Monteiro, investira 65 cestos de seda para serem vendidos no Japão. ${ }^{12}$

\section{O relicário com o agnus dei filiava Violante na religião católica, ao passo que os instrumentos de mesa a remetiam para a cultura europeia}

Outro Domingos Monteiro, o moço (para distinguir de seu homônimo), andava em viagem para Timor, tendo-lhe Antônio dado 200 cruzados para comprar mercadoria. Os negócios que menciona circulavam, portanto, em muitas zonas de costa, compreendidas entre Goa e Japão: Cochim, Malaca, Sião, Timor, Cantão... Pelo testamento, tem-se a impressão de que Antônio Monteiro não tinha bens acumulados, mas tudo era reinvestido no tráfico, com a exceção de alguns escravos, a quem de resto maior atenção é concedida no testamento do que à própria casa de Antônio, que, como vimos, nem sequer declarou onde ficava, deixando apenas implícito que seria em Macau. Os escravos constituíam, à falta de terra cultivável, bens importantes, não só pela ostentação de riqueza que permitiam, mas também pelos serviços que prestavam. Podiam ser alfaiates, barbeiros e até, como no caso de Brás Monteiro, substitutos do dono nos negócios.

\section{Uma capela a cargo da misericórdia do Porto}

Violante não era a única destinatária da fortuna de Antônio. Depois de cumpridos os legados do funeral deste, que atrás mencionamos, e de apartadas as somas de seu dote e do de Isabelinha, a herdeira era a misericórdia do Porto. Antônio queria instituir uma capela com a invocação de Nossa Senhora dos Anjos e da Porciúncula na igreja do convento de São Francisco do Porto, sob a vigilância da misericórdia do Porto, remunerada com 20 mil réis anuais, "para pobres". A administração da capela, no entanto, ficaria a cargo de seu sobrinho Gil Monteiro Pinto, residente no Porto, ou do parente mais chegado por parte do pai. Note-se que, apesar de bastardo, a linha paterna era a preferida de Antônio,

\footnotetext{
"Por provisão do vice-rei de 1554, as naus que iam de Malaca à China eram obrigadas a deixar fiança pagando direitos das mercadorias no regresso, com exceção dos que tivessem licença em contrário emitida por ele ou pelo governador (Rivara, 1992, fasc. 5, parte I, p. 264).

12 Não se encontrou na bibliografia qualquer menção ao fato de a seda poder ser medida em cestos. Provavelmente, estaria por pesar, sendo a unidade de peso da seda normalmente os picols, equivalentes a cerca de 60,5 quilos cada.
} 
talvez por sua importância social, uma vez que lhe garantia o estatuto de fidalgo. Outros haveriam de se valer dele, malgrado sua bastardia, sendo sempre considerados superiores aos simples plebeus, mesmo de nascimento legítimo. ${ }^{13}$

Como era habitual nos testamentos, o testador ia colocando alternativas caso sua vontade inicial não pudesse ser cumprida; se não fosse possível fazer a capela no Porto, o dinheiro seria repartido pelas misericórdias de Cochim, Goa, Lisboa, Porto e Mesão Frio, todas agraciadas com 100 mil cruzados, à exceção do Porto, terra natal de Antônio, a quem destinava o dobro dessa soma. Se ainda sobrasse dinheiro, seria dado para dotes a parentas pobres em Mesão Frio; caso elas não existissem, a mulheres nobres. Deixava ainda 300 cruzados a Gil Monteiro Pinto, seu sobrinho residente no Porto, e ainda outros 50 a uma sobrinha freira no convento de Corpus Christi em Vila Nova de Gaia, Filipa de Seixas. ${ }^{14}$

Como muitos testadores, não bastava a Antônio saldar suas dívidas para com Deus, mas desejava resolver as que tinha contraído com os homens. Deviam ser saldadas mediante "conhecimentos", papéis assinados pelo credor e devedor especificando as quantias em causa, embora Antônio mandasse pagar às pessoas que se apresentassem sem comprovativo, se dessem juramento e fossem dignas de crédito e "de quem se não possa suspeitar velhacaria". ${ }^{15}$ Como se sabe, a confiança era a moeda humana corrente entre os mercadores, e Antônio não fugia à regra. Confiava a familiares seus o que tinha de mais precioso, as mercadorias e as meninas, em detrimento das instituições régias, que repetidamente afastava da execução de seu testamento.

Havia ainda outros legados menores, como mandar cobrir a casa dos lázaros da misericórdia. Ao contrário da Europa, onde a doença se encontrava há muito em recessão, a lepra continuava a grassar no Oriente, pelo que as misericórdias se viram várias vezes na contingência de fundá-las e administrá-las (Sá, 2008, p. 168; Seabra, 2011, p. 194). Para além do dinheiro para o telhado da leprosaria, a misericórdia de Macau receberia cem cruzados.

\section{Os testamenteiros}

Aqueles que os testadores escolhiam para zelar pelo cumprimento de suas últimas vontades eram peças-chave no processo de transmissão das heranças. Antônio escolhia-os em duas etapas: Francisco Mendes de Vasconcelos, o padre Antônio Lopes da Fonseca e Gaspar Leite, bem como seu compadre Antônio Rebelo Bravo, trabalhariam em Macau para reunir sua fazenda, com a ajuda da misericórdia local. A este último competiria fazer chegar o remanescente da herança à misericórdia do Porto, por letra, quando regressasse a Portugal, onde Gil Monteiro Pinto administraria a capela a que se destinava. Este último era portuense e pediu à misericórdia do Porto para administrar

\footnotetext{
${ }^{13}$ Boxer contrasta os historiadores da Índia, João de Barros e Diogo do Couto; o primeiro era ilegítimo, mas de progenitores ambos nobres, e o segundo, de ascendência plebeia (Boxer, 2002, p. 22).

${ }^{14} \mathrm{O}$ cruzado valia 400 réis, pelo que Gil Monteiro Pinto receberia 120 mil réis, e Filipa de Seixas, 20 mil.

${ }^{15}$ AHSCMP, série H, banco 4, livro 29, fl. 28v.
} 
seu morgadio em terras de Portugal em benefício de uma filha que morava em Goa (Basto, 1997, p. 454).

Os testamenteiros de Macau tinham apenas por função fazer chegar à Índia os bens de Antônio Monteiro na nau da carreira; aí entrariam em ação os outros testamenteiros, seus sobrinhos Domingos e Rodrigo Monteiro, que, relembramos, seriam tutores e curadores das duas meninas. Havia ainda uma participação da misericórdia de Malaca como testamenteira, recebendo cem cruzados pagos pela misericórdia de Macau, talvez porque se situasse no caminho de regresso para a Índia. Nesse, como em outros testamentos, era essencial garantir a boa vontade de todos, usando tanto quanto possível de justiça distributiva, não esquecendo ninguém, na devida proporção de seus serviços.

O testamento de Antônio Monteiro punha, portanto, em marcha uma rede de contatos e afetos que ia da Índia a Timor, prescindindo sempre o mais possível da interferência da Coroa. Até esse ponto, a única instituição régia a que Antônio recorreu foi o tabelião. Nenhum testamento escrito era válido se não fosse aprovado por um notário, cuja nomeação era prerrogativa do rei (Araújo, 1997, p. 75). ${ }^{16}$

Antônio concluía seu testamento dizendo que, se o invalidassem, seria o bispo d. Belchior a providenciar para que suas últimas vontades fossem cumpridas. ${ }^{17}$ Nunca os oficiais del rei... Competiria ao então "bispo da China" repartir o remanescente da herança em três partes para três misericórdias: Porto, Mesão Frio e Lamego, sempre para empregar em dotes de parentes suas honradas, e de preferência de sua linha paterna. Qualquer testador sabia bem que o dinheiro que deixasse a uma mulher jovem podia fazer a diferença entre ficar solteira ou tomar estado.

Uma parte crucial do testamento de Antônio Monteiro era aquela em que enunciava uma condição que haverá de ter provocado muito aborrecimento a todos, entre parentes e instituições, vindo a transformar-se em uma questão judicial. Os intervenientes seriam os parentes de Antônio residentes no Porto, por um lado, e contra eles, em Cochim, a família de Violante, entretanto casada. O testamento estipulava que os filhos de Violante seriam os administradores da capela, ou os de seu sobrinho morador no Porto, Gil Monteiro Pinto; em último caso, os parentes mais chegados, que seriam obrigados a residir na cidade.

\section{Entre o Porto e Cochim: a luta pela administração da capela}

Em 1607, a viúva do sobrinho do Porto, Gil Monteiro Pinto, chamada Luísa de Paiva, tomou posse da administração da capela instituída pelo tio (bastardo) do marido, juntamente com seu filho João Álvares de Azevedo, à data menor. A cerimônia ocorreu, como é natural, no interior da igreja do convento de São

\footnotetext{
${ }^{16}$ Ver ainda as Ordenações manuelinas, livro IV, título LXXVI.

17 D. Belchior Carneiro (Coimbra, 1516-Macau, 1583) é considerado o primeiro bispo da China e do Japão, embora fosse apenas administrador apostólico dessas regiões, até ser criada a diocese de Macau em 1576 Governou a diocese até chegar o primeiro bispo, d. Leonardo de Sá, em 1581 (Almeida, 1968, p. 704-705).
} 
Francisco da cidade, onde, como estão lembrados, as missas da capela deviam ser celebradas. Para o fazerem, Luísa e o filho muniram-se de autorização régia, emanada por Filipe II de Portugal (r. 1598-1621), o que demonstra bem a força das influências familiares; todavia, o padrão de juro do qual sairia seu rendimento estava na posse da misericórdia do Porto. Por essa altura já correria a disputa entre os parentes portuenses de Antônio Monteiro e a família de Violante, agora unanimemente tida por sua filha. Como vimos, Antônio não o declarara em momento nenhum de seu testamento, embora tivesse deixado escapar que seus curadores, Domingos e Rodrigo Monteiro, eram seus tios.

Poderá o leitor interrogar-se por que é que administrar uma capela podia ser motivo de disputa. Em boa verdade, esta tinha como fim principal zelar pela alma do instituidor, quando muito pelas almas de seus descendentes. Caracterizava-se por vezes, mas nem sempre, pela edificação de um altar no interior de uma igreja, uma vez que o essencial residia na celebração de sufrágios por alma, na quantidade e nos dias prescritos. Administrar uma capela, portanto, incluía zelar pelo rendimento que possibilitava os sufrágios, contratar celebrantes para dizer as missas, pagar-lhes e verificar que a vontade do instituidor estava sendo cumprida. Trabalho, portanto. Então por que é que, como nesse caso, duas fações diferentes disputaram sua administração? Talvez por duas razões: em primeiro lugar, o rendimento estipulado para a celebração de missas não era à justa, constituindo um rendimento para o administrador. Em segundo, podia estar em causa, como nesse caso, o capital simbólico da linhagem, eventualmente afetado pelo fato de que a administrar a capela estivessem os descendentes de um bastardo, também eles falhos de legitimidade (Violante não era filha de casamento).

Seja como for, em 1607 Violante estava casada e tinha dois filhos, Jerônimo e Antônio (como o avô?), ambos menores de 14 anos. Ela e o marido, João Montes Sarmento, viviam muito longe do Porto, na cidade de Cochim. Por isso mesmo, este último ia escrevendo à misericórdia do Porto e constituiu-a sua procuradora em 1600, mas só em março de 1606 esta aceitou oficialmente o encargo. Seis anos depois...

Francisco Montes Sarmento teve de provar ser casado com Violante, segundo as regras da Igreja Católica, por meio de um processo que requereu audição de testemunhas e teve início em Cochim em dezembro de 1607. A primeira testemunha foi João Vieira de Almeida, cidadão de 40 anos de idade, que confirmou que João Sarmento era casado e recebido em face da igreja com Violante Monteiro, filha de Antônio Monteiro. Outras duas foram Manuel Monteiro, de 47 anos; Simão Carvalho, de 44 anos, ambos cidadãos em Cochim; finalmente, Inácio Moreira, viúvo de 70 anos. O testemunho deste último é o mais interessante, porque declarou ter conhecido Antônio Monteiro há muitos anos na China e ter vindo para Cochim na nau de Domingos Monteiro, onde Antônio veio a morrer, sendo público e notório que trazia uma filha consigo, que era Violante Monteiro. 
Do lado dos litigantes portuenses, devemos notar que tanto Gil Monteiro Pinto como o filho, João Álvares de Azevedo Monteiro, foram em seu tempo irmãos da misericórdia, o que demonstra até que ponto os interesses da confraria podiam se confundir com os de seus membros. ${ }^{18}$ De resto, a misericórdia chegou a afirmar que lhe era indiferente o desfecho da contenda, porque seus 20 mil réis anuais estavam garantidos em um caso e em outro. Não era bem assim, porque os herdeiros de Cochim davam mais...

\section{Aqueles que os testadores escolhiam para zelar pelo cumprimento de suas últimas vontades eram peças- chave no processo de transmissão das heranças}

João Montes Sarmento ganhou a causa em 1608, mas é provável que nem ele nem sua mulher fossem vivos em 1609, porque nesse ano seu filho Jerônimo se habilitou como herdeiro da administração da capela fundada por seu avô no mosteiro de São Francisco do Porto. Sua habilitação data de 24 de novembro de 1609 e foi também levada a cabo em Cochim. ${ }^{19}$ As testemunhas foram Francisco Correia Dantas, casado e morador em Cochim, de mais de 35 anos de idade; Antônio de Leão, também cidadão de Cochim, disse ter de mais de 50 anos de idade; finalmente, Valério Gentil, casado e morador na China, de 48 anos. ${ }^{20}$ Este homem tinha sido precisamente um dos que haviam servido de testemunha quando Antônio Monteiro fizera seu codicilo em abril de 1580 .

Jerônimo, no entanto, não residiria no Porto tal como o testamento de seu avô preconizava; a misericórdia ficaria como sua procuradora e administradora da capela. Vemo-la em 1611 a celebrar contrato com um mestre de obras para construí-la, para além de exigir o pagamento das custas do processo à viúva Luísa de Paiva. ${ }^{21} \mathrm{O}$ remanescente do rendimento do juro de $100 \mathrm{mil}$ réis devia ser enviado a Cochim, e a misericórdia prestou contas a Jerônimo. Intermediária, para além da misericórdia do Porto, sua congênere de Lisboa, que remeteria o dinheiro a Cochim. O rendimento médio anual a remeter a Jerônimo, variável porque as despesas da capela também o eram, cifrava-se em torno dos 36.035 réis. O ano mais baixo foi o de 1634, em que a Coroa retirou quatro meses de juro para suas necessidades, tendo a soma apurada para enviar a Cochim ficado pelos 21.520 réis. Não admira, uma vez que a década de 1630 foi especialmente dura para as finanças da monarquia ibérica... O rendimento anual da misericórdia aumentara agora para 30 mil reis, concedidos

\footnotetext{
8 AHSCMP, série D, banco 5, livro 7.

19 Daqui se depreende que o outro filho, Antônio, tinha morrido. AHSCMP, série H, banco 4, livro 29 , fl. 82.

20 A designação de casado era importante no contexto da Ásia portuguesa, uma vez que designava os homens que se fixavam em um local, aí constituindo família.

${ }^{21}$ AHSCMP, série J, banco 3, livro 1, fl. 23.
} 
por Jerônimo a título de esmola para pobres; sem dúvida, um estímulo suplementar para que a misericórdia desse a devida atenção a seu caso.

Entretanto, chegaram novas de que Jerônimo morrera em setembro de 1635, sem herdeiros, porque a capela passou para o menor que em 1607 acorrera com sua mãe, Luísa de Paiva, a tomar posse da capela na igreja de São Francisco: João Álvares de Azevedo, agora irmão da misericórdia. A partir de 1637, a misericórdia cessou sua administração, limitando-se a receber os 20 mil réis anuais que o testador lhe tinha doado. As missas da capela eram ditas mediante uma soma fixa de 10.500 réis, pagos aos padres de São Francisco. Os frades eram os que menos recebiam, embora tivessem o trabalho de celebrar três missas semanais, o que equivalia a 156 missas anuais...

As mais de 200 páginas do processo de Antônio, no entanto, dificilmente são compreendidas se não lermos o testamento de Domingos Monteiro, em boa parte responsável pela demora do cumprimento das vontades póstumas do primeiro.

\section{Domingos Monteiro, capitão-mor da viagem do Japão}

Passemos a observar Domingos, que Antônio afirma repetidamente ser seu sobrinho, embora, relembremos, esse parentesco não bata certo com as genealogias que falam desse ramo dos Monteiros (ver notas 2 e 6). Não só as genealogias contêm erros (entre involuntários e voluntários ${ }^{22}$ ), mas também as fontes, por seu lado, podem classificar os parentescos de forma diferente de caso para caso: um indivíduo aparece em um momento como sobrinho e, em outro, como primo, por exemplo.

Domingos é mais visível nas fontes exteriores à misericórdia do Porto do que seu tio, Antônio Monteiro. Ao contrário deste último, era filho legítimo, ele próprio afirmando no testamento serem seus pais Antônio Monteiro e Branca da Rocha, moradores em Mesão Frio. É um personagem de alguma importância, dado ter sido capitão da viagem do Japão repetidas vezes no último quartel do século XVI.

Em primeiro lugar, o que era o capitão da viagem do Japão e o que fazia? Que poderes tinha?

Os portugueses conheciam o Japão desde 1542, e desde cedo perceberam que, estando o comércio proibido entre este e a China, podiam realizar lucrativos negócios como intermediários. No entanto, a longa viagem entre Malaca e o arquipélago nipônico pedia um porto de abrigo; daí as várias tentativas dos portugueses no sentido de conseguir licença dos chineses para estanciar em um de seus portos. Não foi fácil, uma vez que a China se fechava ao comércio externo; embora houvesse uma diáspora chinesa espalhada pelo Sudeste Asiático, o Estado chinês não a protegia, preferindo promover um programa de migração em larga escala para os espaços vazios da Ásia central (Parker, 2010,

22 Sobre os interesses políticos e sociais em torno da elaboração de genealogias, leia-se Rêgo (2008, em especial p. 119-217). 
p. 139). Os portugueses acabaram por assentar arraiais em Macau, por volta de 1557 (Loureiro, 2000, p. 543). Apesar de se transacionarem outros produtos, o comércio entre a China e o Japão assentava em uma troca vantajosa: a primeira fornecia as apreciadas sedas, que os japoneses preferiam às suas, e o segundo, a prata, que, como vimos, constituía a base das trocas comerciais na China, e de que esta tinha falta.

Os portugueses cedo transformaram em um monopólio um comércio inicialmente aberto a todos. A partir de 1550, a Coroa passou a restringir o direito de comerciar no mar da China a um capitão-mor da viagem da China e do Japão, que o vice-rei ou o governador do Estado da Índia podiam nomear em substituição ao rei. Escolhia-se geralmente um fidalgo, mas os lucros da viagem podiam ser dados a uma instituição, como um município (Souza, 1991, p. 35).

O capitão-mor detinha amplos poderes: era o chefe de todos os navios e estabelecimentos portugueses a oriente de Malaca; falava em nome do rei de Portugal com as autoridades chinesas e japonesas; e desempenhava a função de provedor dos defuntos e ausentes que não tivessem designado testamenteiros. Tinha geralmente uma nau, que aparelhava à sua custa. Suas atribuições eram mais relacionadas com o comando do que com a navegação propriamente dita, que era pelouro dos pilotos; competia-lhe tomar as grandes decisões, manter a disciplina a bordo e exercer justiça. Até 1587, momento em que passaram a ser nomeados ouvidores para a administração, o capitão-mor foi o poder supremo em Macau. ${ }^{23}$ Sua posição de supremacia não deixou de causar conflitos com o Senado municipal, que posteriormente se conseguiu alcandorar ao comando máximo da cidade, com uma dependência mais fictícia do que real em relação a Goa, que manteria até finais do século XVIII.

A viagem do Japão era anual, e a nau deixava Goa em abril ou maio, com o capitão-mor a bordo. Fazia-se uma escala em Malaca, para abastecer a nau de mercadorias transacionáveis no Japão, e seguia-se para Macau, aonde se chegava entre junho e agosto. Aí, os portugueses eram obrigados a permanecer entre 10 a 12 meses, por uma razão simples: a seda chinesa só podia ser adquirida em Cantão entre janeiro e junho, sendo necessário esperar pelo ano seguinte. Não podiam também partir de Macau no início do ano: tinham de esperar pela monção até finais de junho e princípios de agosto, e levavam 30 dias para chegar ao Japão. Aí permaneceriam até nova monção favorável, que acontecia entre fins de outubro e princípios de março, quando largavam novamente para efetuar a viagem de regresso. Ao todo, a viagem podia demorar até três anos, caso a escala fosse maior em Malaca ou se se perdesse a monção em Macau (Boxer, 1990, p. 29).

Essa longa viagem, a que, como o leitor deve imaginar, não faltavam os imprevistos, explica várias coisas patentes em nossa documentação: em primeiro lugar, que esses homens, apesar de possuírem raízes na Índia portuguesa, tivessem de residir parte do tempo em Macau, onde tinham residência;

${ }^{23}$ Da mesma forma, em Macau, o posto de provedor dos defuntos e ausentes passou a ser de nomeação municipal a partir de 1589 (Boxer, 1990, p. 31). 
que pensassem nas igrejas da cidade para lhes servir de abrigo aos despojos fúnebres ou para lhes encomendar as almas.

\section{Administrar uma capela incluía zelar pelo rendimento que possibilitava os sufrágios, contratar celebrantes para dizer as missas, pagar-lhes e verificar que a vontade do instituidor estava sendo cumprida}

Boxer elaborou duas listas de capitães-mores nas quais Domingos Monteiro surge como capitão da viagem do Japão por quatro vezes: três anos seguidos, de 1576 a 1578, e ainda 1586. Nada diz sobre a quinta viagem, que nos interessa aqui (falta encontrar a nomeação respectiva, que podia ter ocorrido entre 1589 e 1591), mas em contrapartida Domingos aparece em outra lista de Boxer como governador de Macau em 1592, quando na verdade já estava morto. Quanto a 1593, temos já Gaspar Pinto da Rocha nesse papel, o que está correto (Boxer, 1990, p. 273-279); o próprio Boxer refere em outro lado que Domingos Monteiro não chegou a fazer a viagem de 1592, apesar de nomeado (Boxer, 1963, p. 57).

Ao contrário de Antônio Monteiro, um desconhecido, Domingos surge referido em outras fontes históricas. Em 1578, foi um dos primeiros europeus a avistar as costas de Chosen na Coreia, graças a um tufão (Boxer, 1990, p. 53). Lidou também com um dos principais obreiros da unificação política do Japão, Hideyoshi (c. 1537-1598), que o recebeu em julho de 1587, e que muito em breve começaria a hostilizar a presença de missionários cristãos em terras nipônicas. ${ }^{24}$

\section{O testamento de Domingos Monteiro}

Domingos mandou fazer seu testamento em meio a uma viagem ao Japão; era proprietário de apenas metade da viagem, a outra pertencendo a Jacome de Póvoas, com quem dividiria os lucros. Dirigia-se a Macau, uma vez que o fez em Malaca, com data de 22 de junho de 1591, declarando que já ia doente. Na ocasião, encontrava-se em casa de um português, Jorge Nunes, casado. Escreveu o testamento metade por sua mão e a outra por mão de terceiros, talvez em consequência do agravamento de seu estado de saúde. Em todo caso, assinou-o, juntamente com as testemunhas. Nele, manifestou a mesma desconfiança que o tio tinha verbalizado cerca de 11 anos antes: as justiças do rei não deviam interferir na execução respectiva.

Pelo testamento, ficamos sabendo que Domingos, embora não tivesse herdeiros forçados, era casado em Cochim (a avaliar pela ausência do nome da

${ }^{24}$ Sobre Hydeyoshi, ver Boxer (1993, p. 172). O episódio é narrado pelo padre Luís Froes (Fróis, 1976-1984, v. IV, p. 395-396). Ver ainda Biblioteca Nacional da Ajuda, cod. Jesuitas na Ásia, 49-V-3 (t. XXVIII), fls. 8-8v e 11 
mulher, devia já estar viúvo), porque menciona a sogra, de seu nome Francisca Sarmento, o mesmo sobrenome do marido de Violante, que, como sabemos, casou e viveu também em Cochim. Esta última viria também a residir em Cochim, tal como a sogra de Domingos. Não será de excluir portanto que este, na qualidade de tutor, lhe tenha arranjado noivo no interior do grupo familiar da mulher com quem tinha se casado. Relembremos que Domingos Monteiro tinha sido constituído testamenteiro dos bens de seu tio, Antônio Monteiro, juntamente com seu irmão Rodrigo, entretanto desaparecido da documentação, devendo providenciar o casamento de Violante e Isabelinha.

\section{Os bens}

A situação econômica de Domingos parece bem menos próspera de que a do tio Antônio Monteiro. Ainda para mais, seus bens estavam na mão de outras pessoas, e na Índia. O excerto que transcrevemos documenta bem o estado caótico de suas finanças:

[...] eu tenho na Índia 6.400 pardaus de reales pouco mais ou menos ${ }^{25}$ que me devem os contratadores da pimenta e Francisco Lopes de Elvas dos quais ficaram os conhecimentos para os arrecadar deles a Francisco Mendes de Vasconcelos [...] tanto que nosso senhor trouxer as naus do reino e este dinheiro está poticado em 6660 e tantos pardaus ${ }^{26}$ e o remanescente é meu e assim ficou mais ao dito Francisco Mendes um boiãozinho de almíscar que será aquilo que ele disser e assim tenho em Cochim em poder de Pero Afonso aí casado e morador nove cestos de seda que poderão ter 27 e 28 mãos [...] e assim lhe ficaram mais nove barças e meia de louça fina dos quais ele tem mandado para Ormuz (?) [...] e de tudo isto não tenho conhecimento nem assinado seu mas ele (é) tal que dirá a verdade toda que com a pressa da embarcação lho não pedi, e assim mais lhe vendi as minhas casas por retro por preço de dois mil xerafin $\mathrm{s}^{27}$ os quais eu devia à meação da herança que herdou de Maria de Góis que Deus tem, e ele os tomou sobre si e não me deu quitação da casa nem assinado seu disso e assim tenho mais em Cochim três boticas as quais ficarão a Francisca Sarmento minha sogra $[\ldots] .^{28}$

Tal como Antônio Monteiro, Domingos continuava com suas mercancias para além de sua morte: 5 mil patacões deviam ser enviados da China para a Índia em mercadorias, bem como outros 4 mil, que se enviariam à misericórdia

\footnotetext{
${ }^{25}$ Boxer só tem pardau de ouro (equivalente a cerca de 360 réis, e pardau de prata, de valor semelhante ao pardau de tangas ou pardau de larins, 300 réis). Supus que se refere ao primeiro, equivalente ao cruzado e ao real de oito, e fiz as contas da seguinte forma $6400 \times 360=2.304 .000$.

${ }^{26}$ Uma vez que excede o valor inicial de 6.400 pardaus de reales, supus que se trata do pardau de prata, equivalente a 300 réis. Dessa forma: $6000 \times 300$ reis $=1,800.000$ réis.

${ }^{27} \mathrm{O}$ xerafim era uma moeda indo-portuguesa, em teoria equivalente a 300 réis. Assim, as casas foram vendidas por $2.000 \times 300=600.000$ réis.

${ }^{28}$ AHSCMP, série H, banco 6, livro 17, fl. 280v.
} 
de Lisboa para esta enviar à família de Rafael Monteiro que vivia em Castro Daire. ${ }^{29}$ Outro parente?

Em seguida, Domingos falava dos compromissos para com pessoas de suas relações. Por intermédio deles, ficamos sabendo que a nau de um homônimo seu tinha ido a Bengala, tendo lá falecido Diogo Monteiro, de quem ficara de enviar 300 patacões ao Reino. ${ }^{30}$ Sobrava ainda do defunto um "caixão" (arca ou caixa) com pertences seus, que também deviam ser enviados ao pai de Diogo. O testamento estava em Cochim, pelo que se presume que Domingos seria o executor das últimas vontades de Diogo, não sabemos se designado por este, se em sua qualidade de provedor dos defuntos e ausentes.

Outra pessoa que figura entre as preocupações de Domingos era Luís Machorra, também falecido em sua nau, dessa vez no Japão. Ao provedor dos defuntos em Cochim tinha entregado 160 pardaus, ${ }^{31}$ que este devia enviar aos irmãos de Machorra para Almada. Caberia aos testamenteiros de Domingos saber se de fato os tinham mandado e acrescentar ainda cem pardaus doados por este último.

Como outros doadores do império, Domingos distribuía ainda uma série de legados a várias misericórdias: Lisboa (que faria chegar um legado seu a Antônio de Belois), e Goa e ainda Cochim. Nesta última, um deles era de uma mulher chamada Maria de Góis, que o tinha deixado para casar órfãs. Suas funções de capitão da viagem incluíam a de provedor dos defuntos, e, como vemos, Domingos tinha protelado a execução das últimas vontades destes. Para um mercador, não seria inédito usar o dinheiro dos outros adiando sua entrega aos legítimos possuidores. O que nos leva a questionar o valor da confiança tantas vezes propalada como elemento-chave nos meios mercantis. Será que todas essas pessoas tinham efetivamente confiança em Domingos Monteiro, ou apenas que este era uma personagem incontornável pelo controle que detinha da viagem do Japão? Em sua qualidade de capitão-geral, assegurava de fato as comunicações entre vários entrepostos asiáticos onde viviam portugueses...

Não será de estranhar que Domingos, como seu tio Antônio, não declarasse no testamento bens imóveis, para além das habitações que usava quando estava em terra. A casa de Domingos, muito provavelmente, seria sua nau. À falta de terras, os bens de referência eram os escravos. Não os contava, sem dúvida porque se encontravam em outras paragens, podendo reproduzir-se em sua ausência: "eu tenho muitas moças japoas", afirmou. ${ }^{32}$ Todas mulheres. Tinha-as distribuído por várias casas: de Fernão Lobo, seu homem de confiança em Cochim, de uma cunhada, cujo nome não revela, e ainda de Gaspar Pinto da Rocha, seu testamenteiro e herdeiro na metade da viagem do Japão. Este lhes daria a alforria, uma quantia de dinheiro a cada uma (50 pardaus) e lhes

295.000 patacões $\times 360$ réis $=1.800 .000$ réis. 4.000 patacões $\times 360$ réis $=1.444 .000$ réis.

30 Não foi possível identificar nas genealogias e nobiliários se Diogo Monteiro fazia parte dos inúmeros parentes de Domingos. É provável que fosse um dos vários solteiros sem geração que nelas aparecem, sem qualquer outra informação. Trezentos patacões correspondiam a 108.000 réis.

${ }^{31}$ Não especifica de que tipo de pardau se trata. Se for o de prata, 160 × $300=48.000$ réis; se de ouro, 160 × $360=57.600$

${ }^{32}$ AHSCMP, série H, banco 6, livro 17, fl. 281v. 
providenciaria casamento. Para Violante (não sabemos se esta era a filha de Antônio) iriam 400 pardaus. Todas fariam o que Gaspar Pinto da Rocha mandasse, sob pena de perderem a alforria. Separadamente, Domingos dava conta de seus escravos do sexo masculino, sempre sem declarar seu total. Ficavam, à semelhança das raparigas, também forros, mas receberiam apenas 10 pardaus cada um. Entre eles havia os expectáveis japoneses, mas também "lonos" (?). ${ }^{33}$ Fazia várias exceções: o cafre Alexandre, cirurgião, e um barbeiro e comprador que lhe tinham fugido em Cochim, e ainda um alfaiate que o bispo (não refere qual) lhe tinha dado por cativo em Malaca. Mais adiante, Domingos declarava ter em sua casa uma moça chamada Maria, que devia ser especial, uma vez que lhe deixava 3 mil pardaus. ${ }^{34}$ Domingos conservava ainda os três irmãos escravos que seu tio Antônio Monteiro tinha deixado para servirem Violante, o que indica que não tinha seguido à letra o testamento do tio. Alforriava-os, o que por direito não deveria, porque em boa verdade Antônio os tinha deixado à filha 11 anos antes.

Domingos devia saber o que era protelar vontades de defuntos, uma vez que ordenou em seu testamento que as suas deviam ser cumpridas assim que a nau regressasse da viagem do Japão. Esta última continuaria com seu primo Gaspar Pinto da Rocha como capitão, uma vez que Domingos declarava ter-se munido de uma provisão do governador que autorizava a nomeá-lo seu sucessor em caso de morte. A viagem podia ser partilhada no que respeita ao investimento de capitais e lucros, mas a autoridade de seu capitão dizia respeito a um só titular, nomeado pelo rei de Portugal ou pelo vice-rei ou governador do Estado da Índia. Domingos dizia ainda ter autorização do mesmo governador para trazer em sua nau algumas pessoas da China e do Japão, recomendando: "peço-lhe que nisso se haja piedosamente com eles porque o mesmo o houvera eu de fazer" ${ }^{35}$ De fato, sabemos que Domingos levou e recolheu muitas pessoas para o Japão, sobretudo missionários (Fróis, 1976-1984, v. II, p. 47273, e v. IV, p. 207).

Em seguida, o testamento começava a desfiar o rol de homens de sobrenome Monteiro que estavam naquelas paragens: seu sobrinho Antônio Monteiro (um homônimo de nosso primeiro testador) e ainda outro sobrinho, filho do irmão Rodrigo. Para segurança, Domingos nomeava três testamenteiros, que, segundo a mesma ordem, herdariam dele o cargo de capitão-mor se falecessem; entretanto: um deles era, como já referimos, seu primo Gaspar Pinto da Rocha, o segundo Manuel Florim, Antônio Rebelo Bravo (que aparecera 11 anos antes referido por Antônio Monteiro como seu compadre). O testamento foi aprovado no mesmo dia, no tabelião Baltasar Pires, de Malaca, tendo-lhe sido entregue das próprias mãos de Domingos. Em cinco testemunhas, três

${ }^{33}$ Essa palavra deve ter sido mal transcrita para o livro dos testamentos da misericórdia, e seu significado é duvidoso. Por aproximação fonética, poderia designar os jaus, ou jaos, nome dado aos javaneses, podendo a ilha de Java também constituir porto de escala na viagem ao Japão.

34360 réis $\times 3000=1.080 .000$ réis ou 300 réis $\times 3000=900.000$ réis (ver nota 25)

${ }^{35}$ AHSCMP, série H, banco 6, livro 17, fl. 281V 
tinham o sobrenome Monteiro: Álvaro Monteiro, Antônio Monteiro e Nuno Monteiro Coutinho.

As disposições testamentárias de Domingos estavam, no entanto, longe de estar terminadas; nesse mesmo dia, elaborou o primeiro de dois codicilos. Este era bem mais concreto quanto a dinheiros do que o testamento. Especificava o que fazer com os 5 mil pardaus nele referidos, dizendo que pertenciam a nosso primeiro testador, Antônio Monteiro. Dever-se-iam enviar à misericórdia do Porto e ao sobrinho deste, Gil Monteiro Pinto: fica esclarecido que uma das causas do atraso com que esta recebeu o dinheiro se deveu ao fato de terem continuado na posse de Domingos, testamenteiro de Antônio. Isso explica que a primeira notícia da herança de Antônio Monteiro nas atas da misericórdia seja de maio de 1601, em que a mesa decidiu ir buscar os "seis mil e tantos cruzados" (cerca de 2.400 .000 réis) que estavam na misericórdia de Lisboa, já então colocando a hipótese de entrar em litígio com a viúva de Gil Monteiro Pinto, Luísa de Paiva. ${ }^{36}$ Já quanto ao dinheiro de Violante e Isabelinha, tinham-lhes sido entregue, segundo declarava o testamento, 6 mil pardaus a Violante e 1.200 a Isabelinha; tinha ainda enviado outros mil à mãe de Antônio por letra, e pago fretes e direitos relativos à fazenda do tio.

Havia ainda que especificar o que fazer com os outros 4 mil pardaus que mencionava; seriam enviados à misericórdia de Lisboa. Era o momento de beneficiar outros Monteiros, dessa vez residentes em Portugal. Seriam enviados para Castro Daire, para os herdeiros de Rafael Monteiro. Dava a três sobrinhas suas, filhas de Rodrigo Monteiro, seu irmão, 500 pardaus. Do remanescente de sua fazenda, far-se-iam três partes: uma para suas sobrinhas de Portugal, filhas de sua irmã e por alguns parentes pobres; as outras duas partes seriam repartidas pelas misericórdias do Porto e de Mesão Frio. Gaspar Pinto da Rocha receberia 2 mil pardaus, e Rui Monteiro teria 200 taéis.

Voltava a falar de escravos: a "uns surdos", 50 taéis; mandava vender o cafre "panasco" e a "cafra". Assim, sem mais. Inseria agora uma nota emotiva: "e peço ao senhor Gaspar Pinto que o amor que me tinha na vida me tenha na morte e para me desencarregar minha alma" ${ }^{37}$ Note-se a displicência com que falava dos escravos, não os mencionando pelo nome, mas por suas particularidades. A alma, assunto sério, ficava por conta de alguém próximo. Terminava repetindo que suas vontades só deveriam ser executadas depois de a nau regressar da viagem do Japão; o codicilo, declarava Domingos, tinha sido feito com sua própria letra.

Cerca de dois meses mais tarde, em Macau, a 23 de agosto, deu-se andamento a um processo de certificação para validar um segundo codicilo feito a bordo por Domingos Monteiro, que falecera antes de a nau aportar à cidade. Era $1^{\circ}$ de julho desse ano 1591, posterior em cinco dias ao primeiro codicilo. Nele, Domingos fazia novos ajustes, acrescentando o valor de alguns legados de pouca valia: entre outros, seu sobrinho Antônio Monteiro passava agora a receber mil pardaus, e outro sobrinho seu, Luís Pinto, 400. Antônio Pinheiro ficaria com suas casas da China, e com

${ }^{36}$ AHSCMP, série D, banco 8, livro 3, fls. 194-194v.

${ }^{37}$ AHSCMP, série H, banco 6, livro 17, fl. 283. 
cem taéis. Por alturas desse segundo codicilo, já Domingos Monteiro se encontrava incapaz de assinar, uma vez que um jesuíta, Garcia Garcês, o fez por ele. Um total de sete testemunhas assinou o documento: Brás de Araújo, Francisco Martins, Manuel Florim (como vimos, um de seus testamenteiros), Miguel do Couto, Pedro Martins Gaio, Luís Pinto e Antônio Monteiro.

\section{Como outros doadores do império, Domingos distribuía ainda uma série de legados a várias misericórdias}

Na ausência de um notário a bordo, o codicilo teve de ser validado pelo ouvidor em Macau, por meio de uma inquirição de testemunhas, iniciada a 9 de setembro, efetuada pelo respetivo inquiridor acompanhado de um escrivão. ${ }^{38}$ Brás de Araújo foi o primeiro a falar. Esse homem era também originário do Porto, como Antônio e Domingos Monteiro, e deixou bens à misericórdia respetiva (Basto, 1997, p. 454). O inquiridor e seu escrivão deslocaram-se às suas pousadas em Macau, embora se declarasse que Brás morava em Goa. Afirmou ter 57 anos e encontrar-se na nau quando o codicilo fora feito, estando já Domingos incapaz de assinar, pelo que se limitou a fazer seu sinal costumeiro. Em seguida, os dois oficiais foram bater às pousadas de Miguel do Couto, residente em Macau, aí casado, 30 anos de idade, que confirmou as declarações de Brás de Araújo. E continuava o auto de inquirição, agora com a declaração de Manuel Florim, de 50 anos, que se hospedava em casa de Antônio da Costa Caldeira. A quarta testemunha, homem casado e morador em Macau, não declarou a idade. Chamava-se Baltasar Monteiro de Alvarenga e afirmou ser parente do defunto. No dia seguinte, a 10 de setembro de 1591, foi a vez de o inquiridor Gaspar Fernandes ir a casa de outro portuense de origem, Pedro Martins Gaio, também casado e morador de Macau, que declarou ter 31 anos de idade. Também estaria presente a bordo, uma vez que declarou ter visto o defunto fazer o codicilo, e fez declarações semelhantes às das outras testemunhas. Três dias depois, saiu a sentença do ouvidor Damião Gonçalves validando todos os documentos relativos às vontades testamentárias de Domingos Monteiro, incluindo esse segundo codicilo. O ouvidor passou então uma carta comprovativa a pedido do agora capitão-mor Gaspar Pinto da Rocha.

\section{De Macau ao Porto: as reviravoltas da burocracia régia}

Concluído o processo em Macau, a viagem da testamentaria seria agora longa e demorada. Só mais de dois anos mais tarde, a 24 de novembro de 1593, é que a Relação de Goa procedeu ao treslado do auto. Mais cinco anos depois, em 12 de dezembro de 1598, estaria concluído o processo juízo de residência. Tratou-se de um processo de verificação do exercício de cargo de capitão-mor da viagem do

\footnotetext{
${ }^{38} \mathrm{Na}$ falta de validação notarial, testamentos e codicilos eram submetidos à autoridade judicial (Ordenações manuelinas, livro 4, título LXXVI, §3).
} 
Japão: na condição de servidor da Coroa, os bens e a atuação de Domingos estavam sujeitos a uma inspeção, destinada a comprovar que o cargo tinha sido desempenhado sem prejuízo do rei de Portugal. Quando fez seu testamento, Domingos não poderia ter sabido que iria ser assim escrutinado, uma vez que a decisão de 8 de abril de 1592 da Relação de Goa para se tirarem residências aos capitães das viagens foi posterior à sua morte. No assento da Relação, referia-se à viagem do Japão, e seu capitão nesse ano, bem como o que tinha servido no ano anterior, que, por nossas fontes documentais, seria o próprio Domingos Monteiro. Mencionavam-se as desordens que os capitães faziam em detrimento do bem comum, embora não se especificassem (Rivara, 1992, fasc. 5, parte III, p. 1293-1294). Pelo tom desse diploma, e pelo próprio fato de as justificações ultramarinas terem começado a vigorar no momento da morte de Domingos, percebe-se que a coroa não andava satisfeita com o trabalho dos capitães da viagem do Japão.

Doze anos depois dessa sentença, a 18 de outubro de 1610, a misericórdia do Porto recebeu finalmente um treslado da documentação, embora já estivesse na posse do dinheiro da herança desde 1604. A essa altura, recebeu 1.839.600 réis (e não os 2.400.000 inicialmente previstos), vindos da misericórdia de Lisboa, destinados a comprar um padrão de juro. ${ }^{39}$

Devemos, no entanto, confirmar o que dissemos no início: Domingos Monteiro tinha pouco de seu; o dinheiro que deixava pertencia a heranças de outras pessoas. A mais substancial era do primeiro testador que analisamos, seu tio, Antônio Monteiro, que tinha conservado no giro de seus negócios até à sua morte. Embora a misericórdia do Porto não recebesse nada como herdeira de Domingos, encaixava finalmente a herança de Antônio Monteiro. Foi apenas a partir do fim do processo da justificação ultramarina de Domingos Monteiro que a misericórdia pôde finalmente contratar a construção da capela de Nossa Senhora da Porciúncula.

Domingos deixou fama de rico, apesar de morrer sem fortuna própria. Tal como sucedia sempre que estava em causa a perspectiva de receber dinheiro, alguns familiares seus interpuseram queixa. Os herdeiros de uma irmã sua pretenderam um padrão de juro de 15 mil réis no almoxarifado de Vila Real, alegando que ele tinha enviado uma carta em que o doava. ${ }^{40}$

\section{Que conclusões se podem tirar desses processos?}

Em primeiro lugar, há de se considerar que ambos os testamentos nos deram informações sobre a forma como esses homens viveram: no trato marítimo, passando a maior parte de suas vidas a bordo, em uma circulação incessante de pessoas e bens entre a Índia portuguesa e a Ásia do Sudoeste. Mas também sobre as relações interpessoais que estabeleciam com seus companheiros de negócio, por vezes de forma duradoura, cobrindo grandes distâncias juntos e encontrando-se em locais distintos do litoral asiático. Hoje Macau, amanhã Malaca, Cochim ou Goa. Constituíam redes comerciais, alicerçadas também em laços de família; muitos desses homens, como vimos, eram de sobrenome

${ }^{39}$ AHSCMP, série E, banco 1, livro 10, fl. 106.

${ }^{40}$ AHSCMP, série J, banco 3, livro 1, fl. 26. 
Monteiro, ou famílias aparentadas (Pinto, Alvarenga etc.), originárias do Porto ou da região do Douro. Outros, ainda, não eram parentes, mas provinham da mesma cidade - casos de Brás de Araújo, Antônio Rebelo Bravo ou Pedro Martins Gaio. Robert Rowland caracterizou a emigração do Entre Douro e Minho até meados do século XIX, entre outros aspetos, como sendo quase exclusivamente masculina e composta por filhos de famílias relativamente prósperas, que iam sendo chamados para os territórios de emigração pelos tios (Rowland, 1998, p. 347 e 355). Pensamos que esse esquema pode ser aqui aplicado, talvez lhe acrescentando a mistura entre legítimos e bastardos que nossos dois testadores documentam.

Entre os mercadores aqui tratados, a propriedade mais importante é constituída por bens móveis, sobretudo dinheiro e mercadoria, sempre em circulação pelo trato marítimo. É sobretudo por meio dos escravos que se manifesta a qualidade de suas pessoas, porque, na falta de possibilidade de ostentar riqueza imóvel, estes tornariam visível o poder e o estatuto desses mercadores. Era também com eles que podiam eventualmente desenvolver laços familiares, como o caso de Antônio bem documenta, em que a condição de suas mulheres, a mãe de Violante, Maria Monteiro, e Isabelinha, filha de um sobrinho seu, é indeterminada, não se sabendo se continuavam escravas ou tinham sido alforriadas.

Na longínqua Macau, e muito mais no Japão, era admissível que a autoridade régia não se fizesse sentir de forma intensa. Contudo, a necessidade de transferir riqueza para a metrópole, em boa parte por causa das obrigações de alma, fazia com que a Coroa se tornasse um interlocutor indispensável. Muito embora nossos dois doadores confiassem mais nas misericórdias do que nos agentes do rei, não podiam escapar totalmente à ingerência destes últimos. Testamentos e codicilos deviam ser aprovados e validados por notários, e até por ouvidores, que podiam submetê-los a inquirições de testemunhas. No caso de Domingos Monteiro, o juízo de residência, posto a funcionar pouco depois de sua morte, fiscalizou a execução de seu testamento, porque sua função era observar se havia irregularidades no exercício de seu cargo. Por todos esses obstáculos, a que se somavam os longos tempos das viagens de ida e volta de Lisboa para a Ásia, compreendem-se as demoras relacionadas com a transmissão de propriedade. Se lhes juntarmos os conflitos de interesses entre potenciais herdeiros, por vezes separados por vários oceanos de distância, como o caso de Antônio Monteiro documenta, percebemos as dificuldades envolvidas. Só o fato de estarem em causa bens materiais - e vimos como os testadores procuravam distribuir riqueza por um grande número de pessoas e instituições, para comprometerem o máximo de entidades - justificava que esses processos fossem levados a bom termo. As misericórdias, como parte envolvida, não deixavam de tentar lucrar com as testamentarias, em nome dos pobres, é certo. Mas com gastos humanos e materiais muito consideráveis.

Isabel dos Guimarães Sá é membro integrado do Centro de Estudos de Comunicação e Sociedade (CECS), também da Universidade do Minho. 


\section{Referências bibliográficas}

ALMEIDA, Fortunato de. História da Igreja em Portugal. Edição de Damião Peres. Porto: Civilização, 1968.

ARAÚJO, Ana Cristina. A morte em Lisboa: atitudes e representações, 1700-1830. Lisboa: Notícias, 1997.

BASTO, Artur de Magalhães. História da Santa Casa da Misericórdia do Porto. Porto: Santa Casa da Misericórdia, 1997. v. I.

BOXER, Charles Ralph. Fidalgos no Extremo-Oriente. Lisboa: Fundação Oriente, 1990. . Opera Minora. Edição de Diogo Ramada Curto. Lisboa: Fundação Oriente, 2002. v. II. . The Christian century in Japan 1549-1650. Manchester: Carcanet Press, 1993.

. The great ship from Amacon: annals of Macao and the Old Japan Trade, 1555-1640. Lisboa: Centro de Estudos Históricos Ultramarinos, 1963.

BRITO, Pedro de. Patriciado urbano quinhentista: as famílias dominantes do Porto, 1500-1580. Porto: Câmara Municipal/Arquivo Histórico, 1997.

BROCKEY, Liam. A Garganta: the China Jesuits and the College of Macau, 1579-1623. Revista de Cultura (Macau), v. 5, p. 44-55, 2003.

BROOK, Timothy. Vermeer's Hat: the seventeenth century and the dawn of the global world. Londres: Profile, 2009.

FREITAS, Eugénio de Andrea. Domingos Monteiro, mercador quinhentista no Extremo Oriente. Revista da Universidade de Coimbra, v. XXXVI, p. 389-393, 1991.

FRÓIS, S. J. (Padre Luís Froes). História de Japam. Lisboa: Biblioteca Nacional, 1976-1984. 5 v. GAIO, Felgueiras. Nobiliário de famílias de Portugal. Braga: Pax, 1939. t. XIX-XX.

LOUREIRO, Rui Manuel. Fidalgos, missionários e mandarins: Portugal e a China no século XVI. Lisboa: Fundação Oriente, 2000.

MORAIS, Cristóvão Alão de. Pedatura lusitana. 2. ed. Braga: Carvalhos de Basto, 1998.

ORDENAÇÕES manuelinas. Lisboa: Gulbenkian, 1984. 5 livros.

PARKER, Charles H. Global interactions in the early modern age. Cambridge: Cambridge University Press, 2010.

PATTERSON, Orlando. Slavery and social death: a comparative study. Cambridge, Mass.: Harvard University Press, 1982.

PENALVA, Elsa. As lutas pelo poder em Macau, c. 1590-c. 1660. Tese (Doutorado), Universidade de Lisboa, Lisboa, 2005.

RÊGO, João de Figueirôa. Reflexos de um poder discreto. Lisboa: Caleidoscópio, 2008.

RIVARA, Joaquim (Ed.). Archivo Portuguez Oriental. Nova Delhi: Asian Education Services, 1992.6 t., $10 \mathrm{v}$.

ROWLAND, Robert. Velhos e novos Brasis. In: BETHENCOURT, Francisco; CHAUDHURI, Kirti (Org.). História da expansão portuguesa. Lisboa: Círculo de Leitores, 1998. v. IV, p. 303-373.

SÁ, Isabel dos Guimarães. Charity, ritual and business at the edge of empire: the Misericórdia of Macao. In: BROCKEY, Liam M. Portuguese colonial cities in the early modern world. Farnham: Ashgate, 2008. p. 149-176.

. Child abandonment in Portugal: legislation and institutional care. Continuity and Change, v. 9, n. 1, p. 69-89, 1994.

SEABRA, Leonor Diaz de. A misericórdia de Macau (séculos XVI a XIX): irmandade, poder e caridade na idade do comércio. Macau/Porto: Universidade do Porto, 2011.

SOUZA, George Bryan. A sobrevivência do império: os portugueses na China (1630-1754). Lisboa: Dom Quixote, 1991. 